\title{
Health Policies and Ecological Management of Hospital Waste in Ivory Coast: Case of the Hospital and University Center (CHU) of Cocody (District of Abidjan)
}

\author{
BAH Mahier Jules Michel ${ }^{*}$ \& AGOBE Ablakpa Jacob ${ }^{2}$
}

\footnotetext{
${ }^{1}$ Master-Assistant, Institute of Ethno-sociology (IES)-UFR/SHS, Félix Houphouet-Boigny University, Abidjan, Côte d'Ivoire

${ }^{2}$ Master-Assistant, Institute of Ethno-sociology (IES)-UFR/SHS, Félix Houphouet-Boigny University, Abidjan, Côte d'Ivoire
}

DOI: $10.36347 /$ sjahss.2020.v08i01.002

| Received: 06.01.2020 | Accepted: 13.01.2020 | Published: 16.01.2020

*Corresponding author: BAH Mahier Jules Michel

\section{Abstract}

This study examines the factors explaining the dysfunction observed in the management of medical waste in the autonomous district of Abidjan in general but specifically in the Cocody University Hospital Centre (CHU). The study mobilised a dual qualitative and quantitative approach with adequate survey techniques in this case, document review, observation, semi-directive interviews and questionnaire. This enabled us to arrive at the following results: The informal management of medical waste at the Cocody University Hospital is linked to non-compliance with the normative framework published by the Ministry of Health and Public Hygiene. In addition to this, there are socioeconomic issues surrounding medical waste, notably the method of awarding contracts to service provider companies. Thus, the actor placed in the social medical field, develops strategies outside the normative framework to preserve its interests at all points of view.

Keywords: Health policy, Ecological management, medical waste, Hospital and University Centre, Ivory Coast. Copyright @ 2020: This is an open-access article distributed under the terms of the Creative Commons Attribution license which permits unrestricted use, distribution, and reproduction in any medium for non-commercial use (NonCommercial, or CC-BY-NC) provided the original author and source are credited.

\section{INTRODUCTION}

Medical waste is generated by health care services, analytical laboratories, surgical services (human remains) and other ancillary services. Their poor management often leads to health problems such as nosocomial infections. Globally, an estimated 12 billion injections are administered each year, and not all the syringes and needles that result are disposed of properly. Of all the waste generated by health care in sub-Saharan Africa, $20 \%$ is a threat to public health. This rate is generally made up of infectious waste, which represents $15 \%$ for anatomical parts (human remains), sharps at $1 \%, 3 \%$ of the percentage is assimilated to chemical products and finally $1 \%$ is estimated to be ecotoxic waste and radio-active products and heavy metals [1].

Like the West, Africa is also affected by the phenomenon of poor management of waste and hospital user products. Indeed, in June 2000, 6 children who had played with glass bulbs were diagnosed with the mild form of smallpox vaccine virus (acute radiation syndrome), 28 others suffered severe rabies burns. Similar accidents occurred in Algeria in 1978 and
Morocco in 1983 due to a lack of proper management of health care waste, which resulted in accidents as described above.

In August 2006, an investigation led by Professor Soukchal epidemiologist at the Benin hospital was carried out in 59 hospital establishments; one establishment out of three does not have a waste storage place; $29.4 \%$ have intermediate premises in the services and $25 \%$ have them outside the service. In the grouping areas outside the services; $68 \%$ of the health structures deposit waste bags on the ground; $23.3 \%$ in closed garbage niches; $26.3 \%$ in open metal containers and $23.1 \%$ in closed metal containers [2].

In addition, other figures indicate that $41 \%$ of hospitals have rubbish heaps on the ground and $12 \%$ group them outside; $26.3 \%$ have water points next to the grouping area; and $25.2 \%$ dump waste in the open. The risk to anyone in contact with hospital care waste is enormous. In $42 \%$ of services in Benin, health care waste is stored in the health care rooms, in other health centres on window sills, behind the door or under the stairs. In $68 \%$ of the hospitals, staff work with bare hands (without gloves). This environment in which 
hospital waste is found constitutes a risk of Nosocomial Infections (NIs) to patients who are particularly vulnerable to infections. These infections are recognized as major problems in Public Health due to their frequency, cost and severity. A hospitalized sick person risks contracting nosocomial infection at $7 \%$ but it is high at $30 \%$ in the intensive care unit which occurs 48 hours after admission (Aline, idem). Most African countries are not interested in waste quantification. Moreover, they do not declare nosocomial infections as such for fear of guilt.

Also in the Ivorian context and in order to harmonize the sanitary waste management chain, the Ministry of Health has defined a policy to regulate it in health facilities: It is the order $n^{\circ} 131$ MSHHP/CAB/DGHP/DRHP of June 3, 2009 regulating the management of sanitary waste in Côte d'Ivoire. Also an environment code of the law $\mathrm{N}^{\circ} 96-766$ of 03 October 1996. Biomedical waste production figures for public health structures are around $8750 \mathrm{~kg} /$ day or 3194 tonnes /year. For the cities of Abidjan, the production is estimated at $5156 \mathrm{~kg} /$ day, the $\mathrm{CHU}$ produce about $674 \mathrm{~kg}$, the $\mathrm{HG} 17.8 \mathrm{~kg}$, the basic establishments $641 \mathrm{~kg}$ and the private structures 3823 $\mathrm{kg}$. This waste is not always disposed of safely and often ends up in landfills. Those who handle it are pricked by needles and sometimes contract HIV and hepatitis [3].

Despite this environmental code and the decree that has been put in place, waste management remains a problem at the Cocody University Hospital. Indeed, when the hospital opened its doors in 1970, waste management was assigned to the boys and girls in the wards. They did not receive any training in sanitary hygiene and the waste produced by the hospitals was at the Akouedo public dump. But in 2009, the State, aware of the risks related to sanitary waste, passed a decree setting out the management standards. It is in application of this law that the Cocody University Hospital has equipped itself with an incinerator and a treatment plant. Waste management is then entrusted to service providers, with the creation of a hygiene department to supervise hygiene activities and train healthcare staff and service providers in hospital hygiene. Thus, in 2010, several service provider companies such as Junel, Jandi, Gossanchim, Nesti, Eida were involved in the management of sanitary waste at the Cocody University Hospital [4].

After two years of operation of the treatment plant, it broke down. Since then until today, liquid hospital waste (wastewater, biological products, blood, detergents) is discharged into nature without being treated. The population is also exposed to the risk of contamination of all kinds (HBV, HIV, typhoid fever, cholera) due to the continuous pollution of these discharges into nature.
Waste is not always sorted at the source of production. Indeed, during our exploratory investigation, it emerged that the service companies are selected through a call for tenders set out in specifications drawn up by the management of the university hospital, which stipulates the clauses of the contracts for the management and removal of waste. The waste produced at the CHU is of several types: household and assimilated waste (leftover food, paper), infectious waste (liquid waste, soft waste, anatomical waste, sharp sharps waste) and chemical and pharmaceutical waste (leftover medicines and expired medicines). And the sorting of these wastes must be carried out as follows; household and similar wastes must be disposed of in black bins with black bags, soft infectious wastes in bins with yellow bags, sharps waste in safety boxes and pharmaceutical -chemical wastes their destruction is the responsibility of the pharmacy. Waste is sorted by the nursing staff during production. Packaging, pre-collection, collection and transport of waste is done by Gossanchim service agents. The elimination of infectious waste is done by the hygiene service through the handlers by incineration. Household and similar waste is removed by a service provider called EIDA (Entreprise Ivoirienne D'aide en Assainissement) for landfill. For the same exploratory work done in the grouped emergencies and the delivery room, we found that despite the presence of different receptacles, the waste is not sorted.

First of all, the assimilated waste and the infectious waste are in the same bin, the placentas mixed with the assimilated waste. Then, the safety boxes overflow and spill onto the treatment trolleys, no shed for central waste storage. Finally, the liquid water is not treated, the syringes are deposited on the washbasins. The non-sorting of waste at the source means that the waste that is supposed to be destroyed is at the dump, and the collectors also deposit infectious waste in the trunk of assimilated and household waste. These observations cited above indicate a real problem of waste management and this exposes both the human and animal environment. This induces a weakness from an institutional point of view in waste management since the normative framework edited by governments remains inoperative and waste management practices at Cocody University Hospital seem more informal. This leads us to wonder about the persistence of this informal practice in the management of hospital waste in this health structure from production to disposal. So what are the factors explaining the dysfunction observed in the management of waste produced at the Cocody University Hospital? What is the level of knowledge of the players in terms of hospital waste management policy? What are the mechanisms for managing hospital waste at Cocody University Hospital? What are the socio-economic issues related to hospital waste management? 
Based on the structuralism of Alpe et al., [5] which is a fundamental theoretical current of systemic analysis. This structural approach explains social phenomena from social networks. This allows us to decipher the relationships between actors, to understand the position of actors within the network and to study the general shape of the network. The aim is to study the structure where the actor is studied by the links he builds with other actors. In short, the structural analysis of a network makes it possible to evaluate the structure of a network and to provide explanatory elements regarding the actor's behaviour. In the context of this study, structural analysis allowed us to identify the rules and norms that codify and guide the behaviour and opinions of social actors in the management of medical waste. Indeed, the systemic approach also allowed us to identify the mechanisms of the actors' approaches to health policy and the ecological management of hospital waste at the Cocody Hospital and University Centre (CHU).

Hospital waste management in Côte d'Ivoire is a major public health problem. It has been the subject of many scientific studies already carried out in the world and is currently the subject of great mobilization on the part of political actors and populations to work towards good health awareness. The reflection that this phenomenon of health policy and the ecological management of hospital waste at the Cocody Hospital and University Centre (CHU) today inspires us is of great interest and complements the scientific studies already carried out.

From a scientific point of view, we believe that criticism of the treatment of customers in the emergency department would contribute to enriching the field of sociology of the therapeutic itinerary and sustainable human development. For, health can be perceived as a complete well-being without which the individual cannot carry out any activity in society.

\section{METHODOLOGY}

The study was carried out in the District of Abidjan. The survey was conducted over a period of one month. The choice of the Cocody University Hospital is due to the fact that this health institution houses a hospital waste management service. The resource persons involved in the survey are the staff in charge of the production, collection, transport and disposal of hospital waste, relatives of patients, administrative staff and the hygiene service. The eligibility criteria for the resource persons interviewed are their status and their roles in hospital waste management.

The method used is documentary research, direct observation, semi-structured interview and questionnaire. The data collection tools are the observation grid, the semi-structured interview guide, and the administration of the questionnaire. The interview guide is administered to administrative staff, the sanitation department, and the questionnaire to health professionals, collectors, relatives of patients, and those involved in disposal.

Thus, this study combined a two-pronged strategy. The quantitative survey was carried out through a relatively light standardized questionnaire based on an accidental sampling of easily accessible people who met specific inclusion criteria. Thus, the accidental sample was made up of 55 participants, including 15 health care personnel, 15 care providers, 15 relatives of the patients, 7 hygiene personnel and 3 administrative personnel, who were selected according to a random procedure. In addition, 2 semi-structured interviews were conducted with groups of stakeholders. In the qualitative survey, the number of interviews was determined by means of theoretical sampling on the basis of the phenomenon of saturation in qualitative research. Thus 5 semi-structured interviews were conducted with the stakeholder groups concerned. The qualitative data were analysed and processed manually. The analysis was then carried out according to the following steps: reading all the transcripts of the interviews; identifying the key words selected; classifying the speeches according to the explanatory levels of the step and manually processing the quantitative data using Excel.

\section{RESULTS}

II-1- Level of knowledge of the actors in terms of health policy as factors explaining the dysfunction in the management of waste produced at the Cocody Chu

II. 1-1- Level of knowledge of the administration's staff in terms of the health policy for the ecological management of hospital waste

\section{1-1-1- Ministry of Health and Public Hygiene's} Hospital Waste Management Guidelines

According to the survey data, more than half of the administrative staff is unaware of hospital waste management guidelines. For some, this is due to the fact that they do not receive these guidelines on time. It emerges that those who have knowledge of the normative framework of hospital waste management constitute $75 \%$ of the respondents and the self-trained ones represent $25 \%$ of the respondents as shown in the figure below.

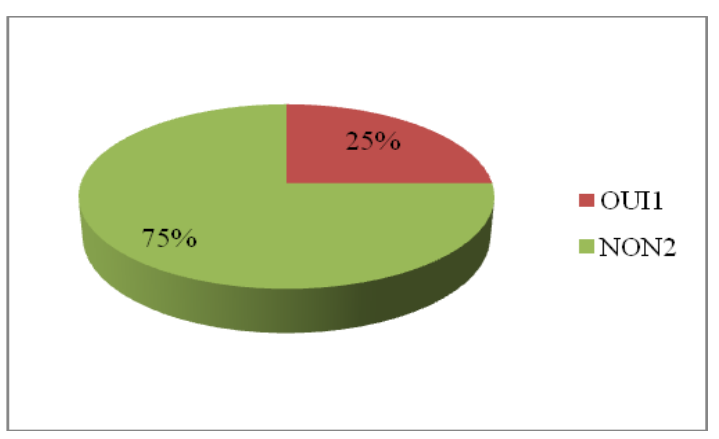


Fig-1: Distribution of administrative staff according to their level of knowledge of the guidelines

Source: 2018 survey

For those who have a notion of these directives through self-training, the words of the respondent C.K. summarize their process of acquisition of information relating to the standards.

Since I've been here, I've only received documents from the directorate of the Ministry of Health relating to waste management. But I train myself when I need something, I do research and with the computer development, we can find everything today, that's how I did research to find out if not for the ministry.

This lack of knowledge of the standards by the administrative staff leads us to question the decree of 03 June 2009 regulating the management of hospital waste in Côte d'Ivoire.

\section{1-1-2- The decree of 03 June 2009 regulating the} management of hospital waste in Côte d'Ivoire

At this stage, it should be noted that $67 \%$ of the actors claim to have taken cognizance of this decree, which moreover is considered by some as the backbone of medical waste management in Côte d'Ivoire. And the respondent J.C in charge of the hygiene service is not on the sidelines.

I know that there are texts on the management of hospital waste that exist to regulate it. When I took office, some documents were sent to me by the director, but so far I haven't read them and that makes me leave.

To this state of knowledge of the decree is also added the question of the environmental code relating to waste management in Côte d'Ivoire. This code should moreover be implemented in hospitals by the hygiene service. However, most of the staff of the CHU-C's Hygiene Department are not interested in it since the logic of designating service providers is ensured by the general management, as the respondent K.D. tells us.

I only prepare the requests for tender. For my part, what concerns the administrative files and the rest is the hygiene service, so we don't manage all that.

It is clear from this speech that the department in charge of hospital hygiene at the CHU-C is restrictive in the application of the normative framework in accordance with the national policy on hospital waste management. And the elaboration of the specifications remains a task of the general management.

II-2-Hospital waste management mechanisms as a determinant of the dysfunction in the management of waste produced at the Cocody hospital chu

For the management of sanitary waste at the identified the hygiene staff who develop the waste management tools, ensure application, training and awareness raising as bonus players on board. Then the healthcare staff who produce waste and sort it at the production stage. And finally, the parents of sick people who produce waste and therefore need to be made aware of the need to dispose of waste in the receptacles.

\section{II- 1- Hospital waste treatment process and material and financial means.}

Almost all the hygiene staff asserts a knowledge of health policies in terms of hospital waste management and the material and financial means of support are insufficient to such an extent that the hygiene service designs tools to control the management of hospital waste according to national standards and its implementation often causes financial means. This is reflected in the words of the respondent D.T.

We develop working tools but not everything is put into practice, for example, the water treatment plant that has broken down is not repaired quickly because of the lack of financial means, so we cannot extend our working tools to this level.

This can also be seen in the diagram below.

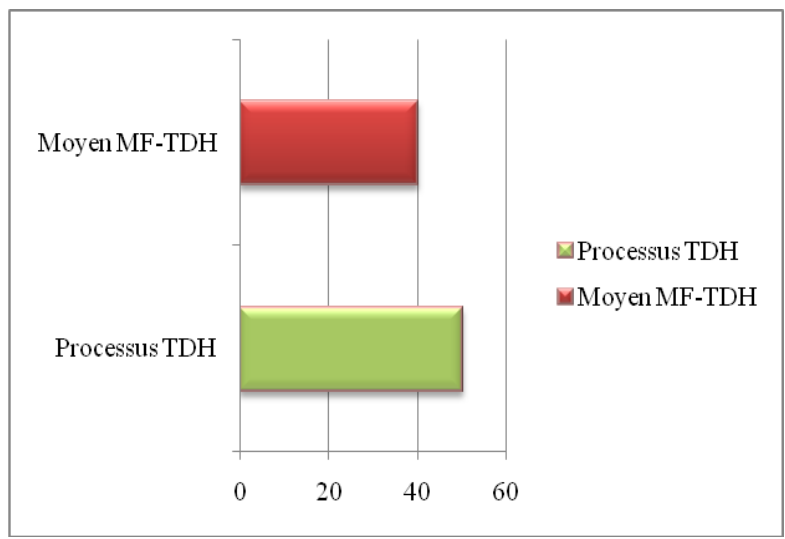

Fig-2: Waste treatment process and accompanying means

\section{II-2- Requirement of waste sorting as a prevention factor}

The staff of the hygiene service requires the sorting of waste to the care personnel as a means of prevention of the risks of contamination and prevention of environmental pollution. This requirement is perceptible through the words of the respondent $\mathrm{H}$. K:

We, the hygiene staff, we demanded sorting insofar as sorting allows us to manage waste well, destruction, generates a lower cost of destruction because here the butane gas that we use at the incinerator for destruction is expensive and also it allows us to avoid accidents with exposure to blood.

\section{II-3- Accessibility to the waste collection network}

Cocody hospital and university centre, we have 
The health care staff claims to have both temporal and spatial accessibility to the waste collection network set up by the hygiene service. Indeed, this accessibility favours a better collection of waste which should lead to its evacuation to the treatment circuit provided for this purpose.

And the position of the respondent S.D. confirms this. We, we put the receptacles with the different colour codes at the disposal of the nursing staff as they are the producers of waste unfortunately they do not sort it. They mix all the waste assimilated as infectious.

In spite of the accessibility to the collection network some actors abandon the waste in the hospital space. They are generally the relatives of patients who transform the hospital universe into an open-air garbage dump. However, each receptacle is colour-coded and depends on the waste to be received. All the patients' relatives mix the infectious waste with the household waste. And maintains that they cannot distinguish between the different colours of the receptacle. This is due to the lack of communication between the hygiene staff and those accompanying the patients. And the words of this respondent J.H. edifies us so well.

Me I mix the waste since I am here it is only one black bag bin which is put at our disposal. But if the people put the different bins with the different colors of bags and explain to us we will use them.

This is due to the lack of different receptacles at their disposal and the lack of awareness. As this respondent K.S. points out:

I mix the waste since I've been here, it's only one black bag bin that is made available to us. But if the people put the different bins with the different colours of bags and explain to us we will use them".

\section{II-3- Socio-economic issues related to hospital waste management favour dysfunction in the management of waste produced at the Cocody chu}

The budget allocated for waste disposal from 2014 to 2015 was one million six hundred thousand CFA francs per month.

While from 2016 to 2018, the budget which was one million one hundred thousand CFA francs, increased from one million two hundred thousand CFA francs per month. Indeed, this budget decrease is due to the lack of consideration given to waste management at the Cocody University Hospital. From 2015 to 2016, there was the extension of the emergencies of the said structure and instead of an increase in the budget, we see a decrease in the budget. Today, the Cocody University Hospital produces seven tons per month or eighty-four tons of household waste per year.
In addition to this waste, the CHU produces twelve tons of infectious waste, of which forty tons are destroyed by the incinerator. Finally, the rest of the waste that is not destroyed is due to the repeated breakdown of the incinerator and a lack of financial resources for repairs.

\section{DISCUSSION OF THE RESULTS}

This study reveals that, first of all, in the area of health policy, the management has a lack of knowledge of the policies. $75 \%$ of the administrative staff at Cocody University Hospital have a lack of knowledge of the Ministry of Health's hospital waste management guidelines. This results in the nonrehabilitation of certain infrastructures that guarantee the health of the populations, specifically the liquid effluent treatment plant. This form of ignorance is also addressed by Justin Ndie [6] who maintains that on the political, institutional level $41.70 \%$ of the health facilities do not have a hospital hygiene unit, $66.67 \%$ of the health facilities did not have a reference document and no health facility produced hospital waste management activity reports. In terms of material resources, $50 \%$ of the health facilities had at least one more or less functional incinerator, $91.70 \%$ of the health facilities had garbage buckets despite their noncompliance. In terms of financial resources, $91.70 \%$ of the health facilities did not receive government funding for hospital waste management. In total, $92 \%$ of the health facilities had low quality hospital waste management. In general, this situation can be explained by an overall lack of hospital waste management policy. Despite some efforts, the quality of hospital waste management in health facilities in the Northern Region remains low. The implementation of an operational plan that takes into account national directives and the problems identified is necessary, as it will improve the quality of hospital waste management in these health facilities.

Then for the hospital waste management mechanisms at the Cocody University Hospital, health professionals behave outside the standards published for waste management. $67 \%$ of the nursing staff at the CHU do not sort waste. They do not sort waste because sorting waste is not their business, they are unaware of the consequences for themselves, visitors and the community, which is the source of all kinds of diseases such as HIV, hepatitis, typhoid fever and dysentery. This form of poor behaviour towards waste management is highlighted by Cuenot [7] who argues that $69 \%$ of health professionals consider their knowledge in terms of the obligation to dispose of their waste from health care activities to be insufficient or deficient. $65.7 \%$ consider that they do not have sufficient information on the possibilities of collection in their sector of practice. The lack of information may help to explain the discrepancy between the number of professionals who sort and those who have a contract with a collection company. If this explanation is 
accepted, it may be a factor justifying information campaigns aimed at healthcare professionals. Belkadi [8] also addresses this issue, supporting the establishment of sustainable management of pharmaceutical medical waste (DMP) at the Marrakech University Hospital, which calls for awareness raising and training on the dangers inherent in DMPs with a view to changing behaviour, establishing a process of continuous improvement in the management of DMPs at the level of health establishments, developing specific DMP treatment channels, establishing a compliance audit of DMP treatment units, and setting up a national and regional DMP management plan. Then Adon Kouadio Patrick [9] points out that the stages of the management process are often not respected by certain structures. The most common waste treatment methods are burning in pits and incineration. For him, there is a need to advocate for capacity building of waste managers and a more ecological environment for health centres and hospitals.

Finally, in terms of socio-economic issues related to waste management, the administrative staff does not give any importance to waste management to the extent that the sewage treatment plant has been inoperative for years, the budget allocated to waste management is insufficient. This is attested by Mohammed Abou Daoudi [10] who states that the management of medical and pharmaceutical solid waste (DSMP) at the Hassan II Hospital in Agadir suffers as a whole from a number of human, material, financial and organisational constraints. The human constraints are reflected in an insufficient number of DSMP collection agents, insufficient training and sensitization of the various stakeholders in the waste management chain and insufficient measures to protect staff (gloves, vaccination, medical monitoring).

Material constraints result in a shortage of waste conditioning equipment. On the financial level, the hospital allocates a small budget for waste management (less than $0.25 \%$ of the hospital's total operating budget, as recommended by the WHO). As for organizational constraints, they are manifested by the lack of a clear hygiene programme, the absence of a waste management plan and the lack of involvement of hospital managers, which results in inadequate supervision, monitoring and evaluation and insufficient coordination between the hospital and local authorities. All these constraints have led to a failure of the DSMP management process at the hospital level, despite the acquisition of a shredding/disinfection machine, and despite the outsourcing of DSMP management. The improvement of DSMP management at the hospital level inevitably involved the removal of constraints and the elaboration of a rigorous plan to ensure the effective adherence of all stakeholders in the DSMP management chain.
This study is a contribution to the sociology of public health problems and the therapeutic route. This study analyses some factors explaining the dysfunction observed in the management of hospital waste at the Cocody University Hospital. It has mobilised a dual qualitative and quantitative approach with appropriate survey tools. This enabled us to arrive at the following results: Hospital waste is an output of the healthcare activity of health establishments. They remain a real public health problem because their management remains a concern for political actors and the training courses that generate them. Despite some efforts, the quality of hospital waste management in hospitals and more specifically at the Cocody University Hospital remains low.

In general, the results show that the overall lack of policy and non-compliance with reference documents, the insufficiency of financial resources allocated to waste management and the weak institutional organisation of the hospital waste management system, and the behaviour of health care staff in not sorting waste are determining factors in the low quality of waste management at the Cocody University Hospital Centre. This study also shows that the effective implementation of a hospital waste management system at Cocody University Hospital requires concerted collective efforts to reduce health risks and environmental pollution. Moreover, the management of hospital waste (from sorting at source to destruction, including policies and financial resources) must take into account national directives and the problems identified and be part of a global policy adapted to the specificity of each health care establishment. Moreover, it must be part of a multidisciplinary logic and requires various adequate financial resources.

\section{REFERENCES}

1. World Health Organization. Atlas of headache disorders and resources in the world 2011. Geneva: World Health Organisation; 2011.

2. Aline K. Étude sur les connaissances, attitudes, et pratiques du personnel sur la gestion des déchets en milieu hospitalier, Institut Supérieur des Techniques Médicales Goma Gradul en Santé Publique BENIN, 2009;130.

3. Diby PA, Saju KA, Jisha PJ, Sarma YR, Kumar A, Anandaraj M. Mycolytic enzymes produced by Pseudomonas fluorescens and Trichoderma spp. against Phytophthora capsici, the foot rot pathogen of black pepper (Piper nigrum L.). Ann Microbiol. 2005 Jan 1;55:129-33.

4. Miezan E, Koffi B. La gestion des déchets sanitaires en côte d'Ivoire: le cas du chu de Cocody de 1996 à 2006, Mémoire de Master Université Felix Houphouët Boigny, 2016; 60.

5. Howard-Alpe GM, De Bono J, Hudsmith L, Orr WP, Foex P, Sear JW. Coronary artery stents and 
non-cardiac surgery. British journal of anaesthesia. 2007 May 1;98(5):560-74.

6. Ndié J, Yongsi HB. Étude de La gestion des déchets hospitaliers dans les structures sanitaires de référence de la région du Nord-Cameroun. European Scientific Journal. 2016 Apr 1;12(11):364.

7. Marie-Paule C. Collecte des déchets d'activités de soins à risque infectieux en milieu extra- hospitalier état des lieux et perspectives dans le département des Yvelines. 2000.

8. Belkadi. Gestion durable des déchets médicaux et pharmaceutiques au CHU de Marrakech, 2013;12.

9. Adon KP. Gestion des déchets biomédicaux dans les structures sanitaires du district d'Abidjan, 2011;90.

10. Mohammed AD. La gestion des déchets solides médicaux et pharmaceutiques à l'hôpital Hassan II d'Agadir, 2008;56. 